\title{
Population Genetic Structure of Wild Boar And Dispersal Performance Based On Kinship Analysis In The Northern Region of South Korea
}

\section{Seung Woo Han ( $\sim$ hsw5034@naver.com )}

Seoul National University College of Veterinary Medicine https://orcid.org/0000-0002-7148-4087

Han Chan Park

Yeongnam Daehakgyo: Yeungnam University

Jee Hyun Kim

Seoul National University College of Veterinary Medicine

Jae Hwa Suh

NIBR: National Institute of Biological Resources

\section{Hang Lee}

Seoul National University College of Veterinary Medicine

\section{Mi Sook Min}

Seoul National University College of Veterinary Medicine

\section{Research Article}

Keywords: Wild boar, Microsatellites, Population Genetics, Dispersal, Kinship Analysis, Conservation Genetics

Posted Date: May 7th, 2021

DOI: https://doi.org/10.21203/rs.3.rs-368091/v1

License: (c) (1) This work is licensed under a Creative Commons Attribution 4.0 International License. Read Full License 


\section{Abstract}

Wild boar (Sus scrofa) is one of the most challenging mammalian species to manage in the wild because of its high reproductive rate, population density, and lack of predators in much of its range. A recent outbreak of African swine fever (ASF) and the transmission into domestic pigs in commercial farms empower the necessity of establishing management strategies of the wild boar population in the northern region of South Korea. A population genetic study, including the dispersal distance estimation of wild boars, is required to prepare fine-scale population management strategies in the region. In this study, both population structure analysis and dispersal distance estimation based on kinship were conducted using 13 microsatellite markers. The results revealed a high level of genetic diversity compared to a previous study. The population was not structured obviously, but there was a slight level of genetic differentiation between groups mainly formed by isolation by distance rather than mountain ridges. The dispersal distance estimation of Korean wild boars based on kinship analysis showed a philopatric pattern in females. However, extensive dispersal ability in both sexes was observed with a considerable proportion. The population genetic status and dispersal traits of wild boars may provide valuable data for planning detailed ASF and wild boar population management strategies in South Korea.

\section{Introduction}

Wild boar (Sus scrofa Linnaeus, 1758) is one of the most extensively distributed, large-sized mammalian species worldwide. Being highly viable and having a high reproductive rate, wild boar spreads its range across most European and Asian regions and the northern part of Africa as native species. Besides, there are introduced populations thriving in the Americas and Australia (Massei and Genov 2004). African swine fever (ASF) is a highly fatal disease for species within the genus Sus, including wild boars and domestic pigs. After the initial outbreak in Georgia in 2007 (Jo and Gortázar 2020), the ASF virus (ASFV) spread quickly all over Eurasia. The virus spread in western European countries in 2014, followed by eastward spread to China in 2018. The first detection of ASFV was near the Demilitarized Zone (DMZ) in the northern part of South Korea in 2019, spreading toward South Korea's southern region. As wild boars can share ASFV with domestic pigs, the spread of disease in wild boars may cause massive economic damage in the swine industry (Cadenas-Fernández et al. 2019).

Therefore, basic information on the species and population biology of wild boars is required to develop a control strategy against ASF in South Korea. A previous study demonstrated that the South Korean wild boar population showed discrete clustering from China, Russia, Indonesia, and Japan, asserting Taebaek Mountain ridges as a gene flow barrier within the South Korean populations (Choi et al. 2014). However, the relatively small number of South Korean samples used in the study is a limiting factor in interpreting the results.

Studies that have described the ecological traits of wild boars in South Korea using ecological methods have been published (Park and Lee 2003; Choi et al. 2006; Lee 2013; Kim et al. 2019). Although several studies about the dispersal ability of wild boars have been conducted in other countries, no such 
information is available in South Korea. A study on the home range size of wild boars in South Korea reported four individuals inhabiting $5.13 \mathrm{~km}^{2}$ on average (Choi et al. 2006). However, this research was conducted with a small sample size using the radio-tracking technique within a limited study area and time frame. Although a recent study about habitat preference demonstrated that wild boars prefer ridge mountain environments with substantial food resources (Kim et al. 2019), further studies must establish detailed control strategies for diseases mediated by wild boars in South Korea. Because the spread of infectious diseases in wild animals is closely linked to the dispersal ability of the animals and the gene flow pattern within the frame of the population structure, information on the dispersal distance and pattern and the genetic structure of wild boars has the potential to contribute to the effective disease control strategy.

Microsatellite marker is a convenient tool for population and ecological genetic studies. These polymorphic markers, which can estimate the recent history of genetic differentiation at the population level, are widely used in numerous studies to demonstrate the population structure of wild animals in South Korea (Lee et al. 2011; Jo et al. 2017; Hong et al. 2018; Lee et al. 2019). Moreover, a set of microsatellite markers was developed for swine biodiversity applications (Committee 2004). The usefulness of these microsatellite markers has been verified by numerous population genetic studies of wild boars (Costa et al. 2012; Choi et al. 2014; Delgado-Acevedo et al. 2021). Dispersal distance estimation with kinship analysis using polymorphic markers has been reported previously for several species (Cayuela et al. 2018). With a sufficient number of samples, this genetic method enables estimating dispersal distance.

This study investigated the genetic diversity and population structure of the wild boar population in the northern part of South Korea (Gyeonggi and Gangwon provinces) and estimated the dispersal distance based on kinship analysis of 474 wild boar carcass tissue samples using 13 microsatellite markers.

\section{Materials And Methods}

Sample collection

Muscle tissue samples from 474 wild boar carcasses, hunted in Gyeonggi and Gangwon provinces by licensed local hunters from November 2019 until May 2020, were collected by NIBR (National Institute of Biological Resources) for DNA extraction. All the hunting activities were done with a permit from local governments and no specific approval was required for the wild boar carcass sampling in this study. For both genetic structure and distance distribution analyses, samples were divided into 6 geographical groups with similar area sizes (Fig. 1). For the Isolation by Distance (IBD) analysis, 474 samples were reassigned into 24 geographical groups, each group with a minimum of 15 samples in a city size area (Table S1, Fig. S1).

PCR amplification and genotyping 
DNA was extracted using a QuickGene DNA tissue kit (Fujifilm, Tokyo, Japan). Total 13 microsatellite markers developed for swine biodiversity research (Committee 2004) were used. The fluorescent-dyelabeled markers were amplified using a multiplex PCR kit (QIAGEN). PCR was conducted with touchdown method under the following conditions: initial denaturation for $15 \mathrm{~min}$ at $95^{\circ} \mathrm{C}$, followed by 7 touchdown cycles starting from $94^{\circ} \mathrm{C}$ for $30 \mathrm{~s}, 67^{\circ} \mathrm{C}$ for $90 \mathrm{~s}$, and $72^{\circ} \mathrm{C}$ for $60 \mathrm{~s}$, with annealing temperature decreasing by $2^{\circ} \mathrm{C}$ per cycle to $53^{\circ} \mathrm{C}$. The additional 25 cycles were performed at $94^{\circ} \mathrm{C}$ for $30 \mathrm{~s}, 53^{\circ} \mathrm{C}$ for $90 \mathrm{~s}, 72^{\circ} \mathrm{C}$ for $60 \mathrm{~s}$, and a final extension step at $60^{\circ} \mathrm{C}$ for $30 \mathrm{~min}$. PCR products were loaded onto a DNA Sequencer (ABI Prism 3730 XL DNA Analyzer, Applied Biosystems) for genotyping. Allele size was determined using GeneMapper v.3.7 (Chatterji and Pachter 2006).

For sexing, newly developed primers for wild boars that amplify intron 7 flanking regions of ZFX and ZFY genes (Han et al. 2007) were used. The PCR condition for sexing was the same as in the referenced paper. The PCR products were loaded onto EtBr agarose gel to distinguish double bands for males from a single band for females by agarose gel electrophoresis.

Data analysis

Genetic structure analysis

Genotype data from 474 wild boars were integrated with GenAlex v.6.503 (Peakall and Smouse 2006) for obtaining the population genetics parameters such as allele frequencies, expected heterozygosity, and observed heterozygosity under Hardy-Weinberg assumptions. Hardy-Weinberg Equilibrium (HWE) test and null allele test were conducted via GENEPOP v.4.7 (Raymond 1995). The sequential Bonferroni correction was applied to take account of statistical errors for multiple tests (Rice 1989). Genetic structure was estimated with STRUCTURE v.2.3.4 (Pritchard et al. 2000), and an optimal K value was estimated with STRUCTURE HARVESTER using the Evanno method (Evanno et al. 2005; Earl 2012). We used the initial burn-in period of 100,000, followed by 200,000 MCMC (Markov Chain Monte Carlo) iterations with 10 iterations per $\mathrm{K}$. We calculated pairwise $F_{\mathrm{ST}}$ values between each of the 6 preliminary estimated groups with FSTAT v.2.9.4 (Goudet 1995) based on 5,000 permutations. Based on the pairwise $F_{S T}$ values, $N m$ values were calculated with the equation of $N_{m}=1 / 4\left\{\left(1-F_{S T}\right) / F_{S T}\right\}$, as an indirect index of a gene flow. Additionally, Slatkin's linearized pairwise $F_{\mathrm{ST}}$ values were calculated with 10,000 permutations between 24 groups assigned for IBD analysis using Arlequin v.3.5.2.2 (Excoffier et al. 2005). We conducted a Mantel test with 999 permutations using GenAlex v.6.503 to estimate IBD to establish the relationship between genetic and geographic distance matrices.

Dispersal distance analysis

The kinship relationship between individuals was estimated with ML-RELATE software (Kalinowski et al. 2006). This program calculates the maximum likelihood estimates of relatedness among 4 putative relationships: parent-offspring (PO), full-siblings (FS), half-siblings (HS), and unrelated (U). The relationship that is found to be most likely true is selected based on a pair's occupation in " $k$-space," where $k$ represents the possible relationship between two individuals. We selected PO pairs based on the 
confidence set option ( 0.05 level of significance). Based on GPS data, we calculated the linear distance between PO-paired individuals, and the proportion by distance was indicated with deflected line graphs according to sex.

\section{Results}

\section{Genetic diversity}

Using the genotype data of 474 wild boar samples obtained by 13 microsatellite markers, population genetics statistics were calculated as shown in Table 1. The number of alleles ranged from 5 at the locus Sw72 to 12 at the locus S0068 with an average 7.7 alleles/locus. Out of 100 alleles in total, 14 were private ones observed only in a single out of 6 groups. A low proportion of private alleles was observed for all groups, with the highest frequency of $5 \%$ in SGG (Southern Gyeonggi).

Table 1 Descriptive statistics for 13 microsatellite loci of the wild boar population in northern region of South Korea

\begin{tabular}{|llllllll|}
\hline Locus & $N$ & $N_{A}$ & $N_{E}$ & $H_{O}$ & $H_{E}$ & $F_{I S}$ & HWE $P$-value \\
S0026 & 474 & 8 & 5.630 & 0.778 & 0.822 & 0.020 & 0.0289 \\
\hline S0068 & 474 & 12 & 4.129 & 0.732 & 0.758 & 0.021 & 0.2027 \\
\hline S0155 & 474 & 7 & 3.277 & 0.705 & 0.695 & 0.028 & 0.6603 \\
\hline IGF1 & 474 & 6 & 2.285 & 0.544 & 0.562 & 0.015 & 0.0779 \\
\hline Sw240 & 474 & 7 & 4.932 & 0.751 & 0.797 & 0.059 & $0.0085^{*}$ \\
\hline Sw857 & 474 & 6 & 3.096 & 0.599 & 0.677 & 0.063 & $0.0042^{*}$ \\
\hline Sw24 & 474 & 11 & 5.250 & 0.749 & 0.810 & 0.044 & $0.0000^{*}$ \\
\hline Sw632 & 474 & 9 & 3.077 & 0.656 & 0.675 & 0.011 & 0.0521 \\
\hline Swr1941 & 474 & 6 & 2.698 & 0.597 & 0.629 & 0.017 & 0.0328 \\
\hline S0143 & 474 & 7 & 4.322 & 0.698 & 0.769 & 0.066 & $0.0000^{*}$ \\
\hline S0226 & 474 & 10 & 3.420 & 0.684 & 0.708 & 0.023 & 0.0604 \\
\hline Sw72 & 474 & 5 & 3.246 & 0.643 & 0.692 & 0.044 & 0.0119 \\
\hline S0090 & 474 & 6 & 4.118 & 0.736 & 0.757 & 0.007 & $0.0077 *$ \\
\hline Total & 474 & 7.7 & 3.806 & 0.682 & 0.719 & 0.032 & \\
\hline
\end{tabular}

$\mathrm{N}$ : Number of samples, $N_{A}$ : number of alleles, $N_{E}$ : number of effective alleles, $H_{O}$ : observed heterozygosity, $H_{E}$ : expected heterozygosity, $F_{I S}$ inbreeding coefficient, HWE $P$-value: the probability of Hardy-Weinberg 
equilibrium, *Significant after Bonferroni correction $(P<0.01)$

Table 1 presents the wild boar population's genetic diversity at the locus level. Loci S0026 and Sw24 showed higher $H_{E}$ compared to other loci. The HWE test found that 5 out of 13 loci showed a significant difference between observed and expected heterozygosity, with no signs of null alleles. This implies the possibility of existing either substructure or inbreeding within the whole wild boar population. The inbreeding coefficient across all loci $\left(F_{/ S}\right)$ was estimated to be low (a maximum value of 0.066 was recorded for the locus S0143). Specified genetic statistics of 6 groups are described in Table S2.

Genetic Structure

Pairwise $F_{\mathrm{ST}}$ and $\mathrm{Nm}$ values among six groups were calculated to estimate the genetic differentiation and gene flow between groups (Table 2). Both parameters indicated the maximum gene flow between NWGW and SWGW ( 0.0043 and 57.6204, respectively) and minimum gene flow between NGG and SEGW (0.0405 and 5.9213, respectively). In general, the results showed little or no significant genetic differentiation within the population. However, a considerable level of pairwise $F_{\mathrm{ST}}$ was observed between SEGW and groups originating in the northwest region (NGG, SGG, and NWGW) than the other group pairs. The genetic differentiation between western and eastern Gangwon provinces (NWGW and SWGW vs. NEGW and SEGW), mainly divided by the Taebaek Mountains, was not observed (mean pairwise $F_{\text {ST }}$ of 0.0152 and mean $\mathrm{Nm}$ of 22.8602).

Table 2 Pairwise $F_{\mathrm{ST}}$ (below diagonal) and $\mathrm{Nm}$ (above diagonal) between each of 6 wild boar groups

\begin{tabular}{|lllllll|}
\hline Location (Abbr.) & NGG & SGG & NWGW & SWGW & NEGW & SEGW \\
\hline $\begin{array}{l}\text { NGG } \\
\text { (Northern Gyeonggi) }\end{array}$ & & 15.6230 & 33.9497 & 15.2683 & 9.8347 & 5.9213 \\
\hline $\begin{array}{l}\text { SGG } \\
\text { (Southern Gyeonggi) }\end{array}$ & $0.0158^{*}$ & & 21.0629 & 25.9280 & 17.3185 & 9.4249 \\
\hline $\begin{array}{l}\text { NWGW } \\
\text { (Northwestern Gangwon) }\end{array}$ & $0.0073^{*}$ & $0.0117^{*}$ & & 57.6204 & 21.3763 & 9.3102 \\
\hline $\begin{array}{l}\text { SWGW } \\
\text { (Southwestern Gangwon) }\end{array}$ & $0.0161^{*}$ & $0.0096^{*}$ & $0.0043^{*}$ & & 46.9198 & 13.8345 \\
\hline $\begin{array}{l}\text { NEGW } \\
\text { (Northeastern Gangwon) }\end{array}$ & $0.0248^{*}$ & $0.0142^{*}$ & $0.0116^{*}$ & $0.0053^{*}$ & & 17.8791 \\
\hline $\begin{array}{l}\text { SEGW } \\
\text { (Southeastern Gangwon) }\end{array}$ & $0.0405^{*}$ & $0.0258^{*}$ & $0.0262^{*}$ & $0.0178^{*}$ & $0.0138 *$ & \\
\hline
\end{tabular}

*: Significant after pairwise $F_{\mathrm{ST}}$ estimation $(P<0.05)$ obtained with 10,000 permutations. $N m: 1 / 4\{(1-$ $\left.F_{S T}\right) / F_{S T}$, is seen as an indirect index of gene flow 
Pie charts shown in Fig. 1 represent the distribution of genetic clusters throughout the studied sample groups using the STRUCTURE analysis. The structure pattern and the optimal number of genetic clusters were determined within six groups using a Bayesian clustering method. According to the Evanno method, the highest $\Delta \mathrm{K}$ was observed when $\mathrm{K}$ was set to 2 (Fig. S2). Recruiting from the two genetic clusters gradually changed from NGG to SEGW group (Fig. 2). Although there was no obvious clustering within the groups, the difference in the two genetic clusters' contribution in their genotypes is obvious.

In IBD analysis, 24 groups modified according to city-sized scale were used for the Mantel test between geographic and Slatkin's linearized pairwise $F_{\mathrm{ST}}$. Significant correlation between genetic and geographic distances was observed ( $P$-value $=0.001, \mathrm{R}^{2}=0.2098$, Fig. 3 ). This pattern corresponded with the STRUCTURE analysis result, in which the genetic clustering pattern showed gradual diagonal line according to the geographic distances between groups.

Distance distribution through kinship analysis

In total, 139 pairs of PO were selected using kinship analysis across six groups. When gender data were applied, 41 pairs of female-female (FF), 34 pairs of male-male (MM), and 64 pairs of female-male (FM) were found. Under the presumption of the PO relationship, an FF pair was presumed to be motherdaughter, an MM pair was assumed to be father-son, and an FM pair was considered either fatherdaughter or mother-son. As FM pair data contain two possible mixed relationships of father-daughter and mother-son, this study mainly focused on FF and MM data to infer sex-specific dispersal distance. The proportion of the linear distance between PO individuals according to sex is shown in Fig. $4 \mathrm{a}$ and $\mathrm{b}$. About $70 \%$ of all kinds of PO pairs were observed within a $30 \mathrm{~km}$ linear distance (Fig. $4 \mathrm{c}$ and d). In the FF pair, about $60 \%$ were observed in less than $20 \mathrm{~km}$ distance and about $70 \%$ were observed in $30 \mathrm{~km}$ distance (Fig. 4b). In contrast, approximately $40 \%$ of the MM pair distance was less than $20 \mathrm{~km}$ and $60 \%$ was within $30 \mathrm{~km}$, which showed a philopatric aspect of female wild boars. A considerable proportion of long dispersal was also observed. Both $20 \%$ of FF and MM were dispersed more than $30 \mathrm{~km}$, further dispersing more than $50 \mathrm{~km}(5 \%)$.

\section{Discussion}

The genetic diversity, population structure, and dispersal distances at the individual level of the wild boar population in the northern part of South Korea were estimated through genetic analysis. Because ASF is spreading mainly in the study area, the information is expected to give meaningful insight in formulating the disease management strategy. The 13 microsatellite loci analysis results showed that the wild boar population in the study area was not obviously structured, and relatively high dispersal distances were observed.

The genetic statistics of 13 microsatellite markers across the whole population pointed out a slightly higher level of diversity compared to the previous report (current study: $N_{A}=7.7, H_{O}=0.682, H_{E}=0.719$; Choi et al.'s 2014 study with the same set of 13 microsatellite markers: $N_{A}=5.5, H_{O}=0.639, H_{E}=0.666$ ). 
The difference might be explained partially by different sample sizes, different sampling times, or different sampling sites covered. Especially, much more samples were covered in the current study (474 in this study vs. 70 in the 2014 study). Five of 13 loci (Sw240, Sw857, Sw24, S0143, and S0090) showed a deviation of HWE due to heterozygosity deficiency. This generally implicates the possibility of inbreeding, population structure subdivisions within the population (Wahlund effect), or sampling error (Waples 2015).

When the inbreeding coefficient was examined, all markers showed low F/Svalues. The extant wild boar population in most Gyeonggi and Gangwon provinces has recently experienced rapid population density growth (Choe et al. 2020). The population might also have experienced high hunting pressure expediting the dispersal and migration of individuals (Scillitani et al. 2010). Considering these factors, we surmised that the influence of inbreeding was low. Instead, we focused on the possibility of the recent admixture of population substructure being the main reason for Hardy-Weinberg deviation.

There was a slight level of population subdivision by structure analysis. Although a clear differentiation between groups was not observed, a considerable level of genetic distance was seen between the most distant groups (pairwise FST values between NGG and SEGW $=0.0405$ ). Also, the bar plot of $K=2$ from the structure analysis showed a gradual diagonal line between these two groups whose cluster was quite different. These data support our IBD analysis results that the physical distance has the most significant correlation with genetic distance. A previous study suggested that mountain ridges could act as a genetic flow barrier to wild boar populations (Choi et al. 2014), but this assumption appears to be rebutted by our results because the groups divided by the Taebaek Mountains (NWGW and SWGW vs. NEGW and SEGW) showed no differentiation (mean pairwise $F_{S T}=0.0152$ ).

These results correspond with a previous study conducted in Bulgaria (Nikolov et al. 2009), where the Balkan mountain range was not a physical barrier for the genetic flow of the wild boar population in Bulgaria. Still, the main factors contributing to the population structure were both IBD and Thracian Valley. Also, in Croatia, Dinaric Mountains had a weak effect than IBD on the wild boar population differentiation (Šprem et al. 2016). Likewise, the result supports the physical distance rather than mountain ridges contributed to genetic distance. However, it cannot be excluded that the observed low population differentiation level might be caused by a high level of dispersal and migration of individuals promoted by the recent population growth and hunting pressure mentioned earlier.

Dispersal of subadult animals from their native places is an essential contributing factor to transmitting infectious diseases among wild animal populations. Therefore, estimating the dispersal pattern and distance of wild animals can provide an important insight required to control the infectious diseases in wild animals. However, it requires considerable resources to acquire information on the dispersal of largesized wild mammalian species through ecological methods, and there has been little such information for wild boars in South Korea, where ASF is spreading from the DMZ area to the south. Thus, we attempted to infer the dispersal distances of the wild boar population in the northern part of South Korea by estimating the linear distance between PO pairs with the highest relationship based on kinship analysis. 
About $70 \%$ of all PO pairs showed less than $30 \mathrm{~km}$ linear distances. The result implies that wild boars in the northern part of South Korea generally disperse less than $30 \mathrm{~km}$. The results are in accordance with the previous ecological study in Sweden reporting that wild boars disperse $16.6 \mathrm{~km}$ for adult males and $4.5 \mathrm{~km}$ for adult females (Truvé and Lemel 2003).

The distances between F-F pairs most likely reflect the dispersal distances of daughters from their mothers; about $60 \%$ of the F-F pairs were observed in less than $20 \mathrm{~km}$ distance and approximately $70 \%$ of the F-F pairs were observed within $30 \mathrm{~km}$. The distances between M-M pairs most likely reflect the dispersal distances of sons from their fathers; about $40 \%$ of the M-M pair distance was less than $20 \mathrm{~km}$, and about $60 \%$ of the M-M pair distance was less than $30 \mathrm{~km}$. The result implies that the proportion of short distance dispersal $(<20 \mathrm{~km})$ was higher in females $(60 \%)$ than in males (40\%). This is in line with the known gender-dependent dispersal pattern of polygynous mammals; females tend to establish their new territories near their native place (Greenwood 1980).

However, about $20 \%$ of both F-F and M-M pair distances was more than $30 \mathrm{~km}$ and about $5 \%$ of both F-F and M-M pair distances was more than $50 \mathrm{~km}$. Therefore, it appears that the proportion of long dispersal distance $(>30 \mathrm{~km})$ in males and females was quite similar ( 20\%), and approximately $5 \%$ of both males and females dispersed longer than $50 \mathrm{~km}$. The results suggest that a considerable proportion of the wild boar population in the northern part of South Korea disperse long distances regardless of sex. However, we should keep in mind that all wild boar samples used in this study were obtained through hunting activities by local hunters. Consequently, intense hunting pressure over the sample area can increase the animal dispersal rate (Scillitani et al. 2010). More detailed results of PO individuals may be drawn if sufficient information is included in a potential parent-offspring analysis and a sufficient number of markers (15-20 polymorphic microsatellite loci) are used (Kalinowski et al. 2006; Cayuela et al. 2018).

Nevertheless, when a sufficient number of samples are obtained, the dispersal of wild boar males may reach more than $100 \mathrm{~km}$ (Truvé and Lemel 2003). In rare cases, though, even further dispersal of female wild boars was observed. A sounder composed of a 2-year-old sow, a female yearling, and eight piglets was found foraging $100 \mathrm{~km}$ from a predispersal home range for 5 months (Jerina et al. 2014). A sow eventually moved at least $500 \mathrm{~km}$ cumulative distance until death from culling. Yet, in another research performed in Spain, the average dispersal distance of female wild boars $(57.7 \mathrm{~km})$ exceeded males' dispersion (Casas-Díaz et al. 2013). Therefore, the potential existence of very long-dispersing individuals should be considered in formulating a wild boar disease control strategy.

\section{Conclusions}

To collect basic information toward understanding the wild boar population in the northern region of South Korea, this study was conducted to estimate the dispersal distance with kinship analysis, and the genetic diversity and population structure were also investigated with 13 microsatellite markers. The wild boar population showed no apparent signs of genetic subdivision, although a low level of population differentiation was detected. The major factor of genetic differentiation within the study sites was 
physical distance rather than mountain ridges. Most PO pairs showed a short dispersal distance, with a higher tendency of short dispersal in females than in males. However, a considerable proportion of long dispersal cases was observed regardless of sex, suggesting an extensive dispersal ability of wild boars in the northern part of South Korea. Information needs to be considered in planning control strategies against ASF.

\section{Declarations}

\section{Acknowledgments}

We thank Dr. Puneet Pandey for his valuable comments on this manuscript. This work was supported by the grant from the National Institute of Biological Resources (NIBR), funded by the Ministry of Environment (MOE) of the Republic of Korea (NIBR202002111).

\section{Funding}

This work was supported by the grant from the National Institute of Biological Resources (NIBR), funded by the Ministry of Environment (MOE) of the Republic of Korea (NIBR202002111).

\section{Conflict of interest}

The authors declare that they have no conflict of interests.

\section{Data availability}

All datasets generated during the current study are available from the corresponding author on reasonable request.

\section{Code availability}

Not applicable

\section{Author contributions}

All authors substantially contributed to this research. MSM and JHS designed the project. Samples were collected by JHS. SWH and JHK conducted experiments. SWH, HCP, JHK analyzed experiment data. SWH wrote the first draft of the manuscript. All authors (SWH, HCP, JHK, JHS, HL, and MSM) fully participated in the editing process of the manuscript and approved the final manuscript.

\section{Ethics approval}

Not applicable

\section{Consent to participate}


All authors provided informed consent to participate to the present work.

\section{Consent for publication}

All authors provided informed consent to publish the present work.

\section{References}

1. Cadenas-Fernández E, Sánchez-Vizcaíno JM, Pintore A, Denurra D, Cherchi M, Jurado C, Vicente J, Barasona JA (2019) Free-ranging pig and wild boar interactions in an endemic area of African swine fever. Front Vet Sci 6:376. https://doi.org/10.3389/fvets.2019.00376

2. Casas-Díaz E, Closa-Sebastià F, Peris A, Miño A, Torrentó J, Casanovas R, Marco I, Lavín S, Fernández-Llario P, Serrano E (2013) Recorded dispersal of wild boar (Sus scrofa) in Northeast Spain: implications for disease-monitoring programs. Wildl Biol Pract 9:19-26

3. Cayuela H, Rougemont Q, Prunier JG, Moore JS, Clobert J, Besnard A, Bernatchez L (2018) Demographic and genetic approaches to study dispersal in wild animal populations: $\mathrm{A}$ methodological review. Mol Ecol 27:3976-4010. https://doi.org/10.1111/mec.14848

4. Chatterji S, Pachter L (2006) Reference based annotation with GeneMapper. Genome Biol 7:1-10

5. Choe S, Cha RM, Yu DS, Kim KS, Song S, Choi SH, Jung BI, Lim SI, Hyun BH, Park BK, An DJ (2020) Rapid spread of classical swine fever virus among South Korean wild boars in areas near the border with North Korea. Pathogens 9:244. https://doi.org/10.3390/pathogens9040244

6. Choi SK, Lee JE, Kim YJ, Min MS, Voloshina I, Myslenkov A, Oh JG, Kim TH, Markov N, Seryodkin I, Ishiguro N, Yu L, Zhang YP, Lee H, Kim KS (2014) Genetic structure of wild boar (Sus scrofa) populations from East Asia based on microsatellite loci analyses. BMC Genet 15:85. https://doi.org/10.1186/1471-2156-15-85

7. Choi TY, Lee YS, Park CH (2006) Home-range of wild boar, Sus scrofa living in the Jirisan National Park, Korea. J Ecol Environ 29:253-257

8. Committee IFS (2004) Secondary guidelines for development of national farm animal genetic resources management plans. Measurement of domestic animal diversity (MoDAD): recommended microsatellite markers. FAO, Rome

9. Costa V, Pérez-González J, Santos P, Fernández-Llario P, Carranza J, Zsolnai A, Anton I, Buzgó J, Varga G, Monteiro N, Beja-Pereira A (2012) Microsatellite markers for identification and parentage analysis in the European wild boar (Sus scrofa). BMC Res Notes 5:479. https://doi.org/10.1186/1756-0500-5-479

10. Delgado-Acevedo J, Zamorano A, DeYoung RW, Campbell TA (2021) Genetic population structure of wild pigs in Southern Texas. Animals 11:168. https://doi.org/10.3390/ani11010168

11. Earl DA, vonHoldt BM (2012) STRUCTURE HARVESTER: a website and program for visualizing STRUCTURE output and implementing the Evanno method. Conserv Genet Resour 4:359-361. https://doi.org/10.1007/s12686-011-9548-7 
12. Evanno G, Regnaut S, Goudet J (2005) Detecting the number of clusters of individuals using the software STRUCTURE: a simulation study. Mol Ecol 14:2611-2620. https://doi.org/10.1111/j.1365294X.2005.02553.x

13. Excoffier L, Laval G, Schneider S (2005) Arlequin. 3.0 version: an integrated software package for population genetics data analysis. Evolutionary bioinformatics. p. 1

14. Goudet J (1995) FSTAT. 1.2 version: a computer program to calculate F-statistics. J Hered 86:485486

15. Greenwood PJ (1980) Mating systems, philopatry and dispersal in birds and mammals. Anim behav 28:1140-1162

16. Han S-H, Lee S-S, Cho I-C (2007) SINE-like sequence insertion on zinc finger-Y gene and sexual dimorphism in wild boars. J Appl Anim Res 32:165-168.

https://doi.org/10.1080/09712119.2007.9706869

17. Hong YJ, Kim KS, Min MS, Lee H (2018) Population structure of the raccoon dog (Nyctereutes procyonoides) using microsatellite loci analysis in South Korea: implications for disease management. J Vet Med Sci 80:1631-1638. https://doi.org/10.1292/jvms.17-0456

18. Jerina K, Pokorny B, Stergar M (2014) First evidence of long-distance dispersal of adult female wild boar (Sus scrofa) with piglets. Eur J Wildl Res 60:367-370. https://doi.org/10.1007/s10344-0140796-1

19. Jo YS, Gortázar C (2020) African swine fever in wild boar, South Korea, 2019. Transbound Emerg Dis 67:1776-1780. https://doi.org/10.1111/tbed.13532

20. Jo Y-S, Kim H-N, Baccus JT, Jung J (2017) Genetic differentiation of the Korean striped field mouse, Apodemus agrarius (Muridae, Rodentia), based on microsatellite polymorphism. Mammalia 81:297307. https://doi.org/10.1515/mammalia-2015-0152

21. Kalinowski ST, Wagner AP, Taper ML (2006) ML-Relate: a computer program for maximum likelihood estimation of relatedness and relationship. Mol Ecol Notes 6:576-579. https://doi.org/10.1111/j.1471-8286.2006.01256.x

22. Kim Y, Cho S, Choung Y (2019) Habitat preference of wild boar (Sus scrofa) for feeding in cooltemperate forests. J Ecol Environ 43:1-8

23. Lee SM (2013) Home range, diet, and crop damage of wild boar (Sus scrofa) in Geochang county, Gyeongnam, Korea. Dissertation, Seoul National University

24. Lee SM, Moon HC, Jeon HS, Song EG, Woo D, An J, Lee MY (2019) A core set of microsatellite loci for yellow-throated marten, Martes flavigula: a case of inferences of family relationships. Genes Genomics 41:1457-1465. https://doi.org/10.1007/s13258-019-00869-9

25. Lee Y-S, Choi S-K, An J, Park H-C, Kim S-I, Min M-S, Kim K-S, Lee H (2011) Isolation and characterization of 12 microsatellite loci from Korean water deer (Hydropotes inermis argyropus) for population structure analysis in South Korea. Genes Genomics 33:535-540. https://doi.org/10.1007/s13258-010-0166-7

26. Massei G, Genov PV (2004) The environmental impact of wild boar. Galemys 16:135-145 
27. Nikolov IS, Gum B, Markov G, Kuehn R (2009) Population genetic structure of wild boar Sus scrofa in Bulgaria as revealed by microsatellite analysis. Acta Theriol 54:193-205. https://doi.org/10.4098/j.at.0001-7051.049.2008

28. Park C-R, Lee W-S (2003) Development of a GIS-based habitat suitability model for wild boar Sus scrofa in the Mt. Baekwoonsan region, Korea. Mamm Study 28:17-21. https://doi.org/10.3106/mammalstudy.28.17

29. Peakall R, Smouse PE (2006) GenAlEx 6: genetic analysis in Excel. Population genetic software for teaching and research. Mol Ecol Notes 6:288-295. https://doi.org/10.1111/j.14718286.2005.01155.x

30. Pritchard JK, Stephens M, Donnelly P (2000) Inference of population structure using multilocus genotype data. Genetics 155:945-959

31. Raymond M (1995) GENEPOP. 1.2 version: population genetics software for exact tests and ecumenicism. J Hered 86:248-249

32. Rice WR (1989) Analyzing tables of statistical tests. Evolution 43:223-225

33. Scillitani L, Monaco A, Toso S (2010) Do intensive drive hunts affect wild boar (Sus scrofa) spatial behaviour in Italy? Some evidences and management implications. Eur J Wildl Res 56:307-318. https://doi.org/10.1007/s10344-009-0314-z

34. Šprem N, Safner T, Treer T, Florijančić T, Jurić J, Cubric-Curik V, Frantz AC, Curik I (2016) Are the dinaric mountains a boundary between continental and mediterranean wild boar populations in Croatia? Eur J Wildl Res 62:167-177. https://doi.org/10.1007/s10344-016-0989-x

35. Truvé J, Lemel J (2003) Timing and distance of natal dispersal for wild boar Sus scrofa in Sweden. Wildl Biol 9:51-57. https://doi.org/10.2981/wlb.2003.056

36. Waples RS (2015) Testing for Hardy-Weinberg proportions: have we lost the plot? J Hered 106:119. https://doi.org/10.1093/jhered/esu062

\section{Figures}




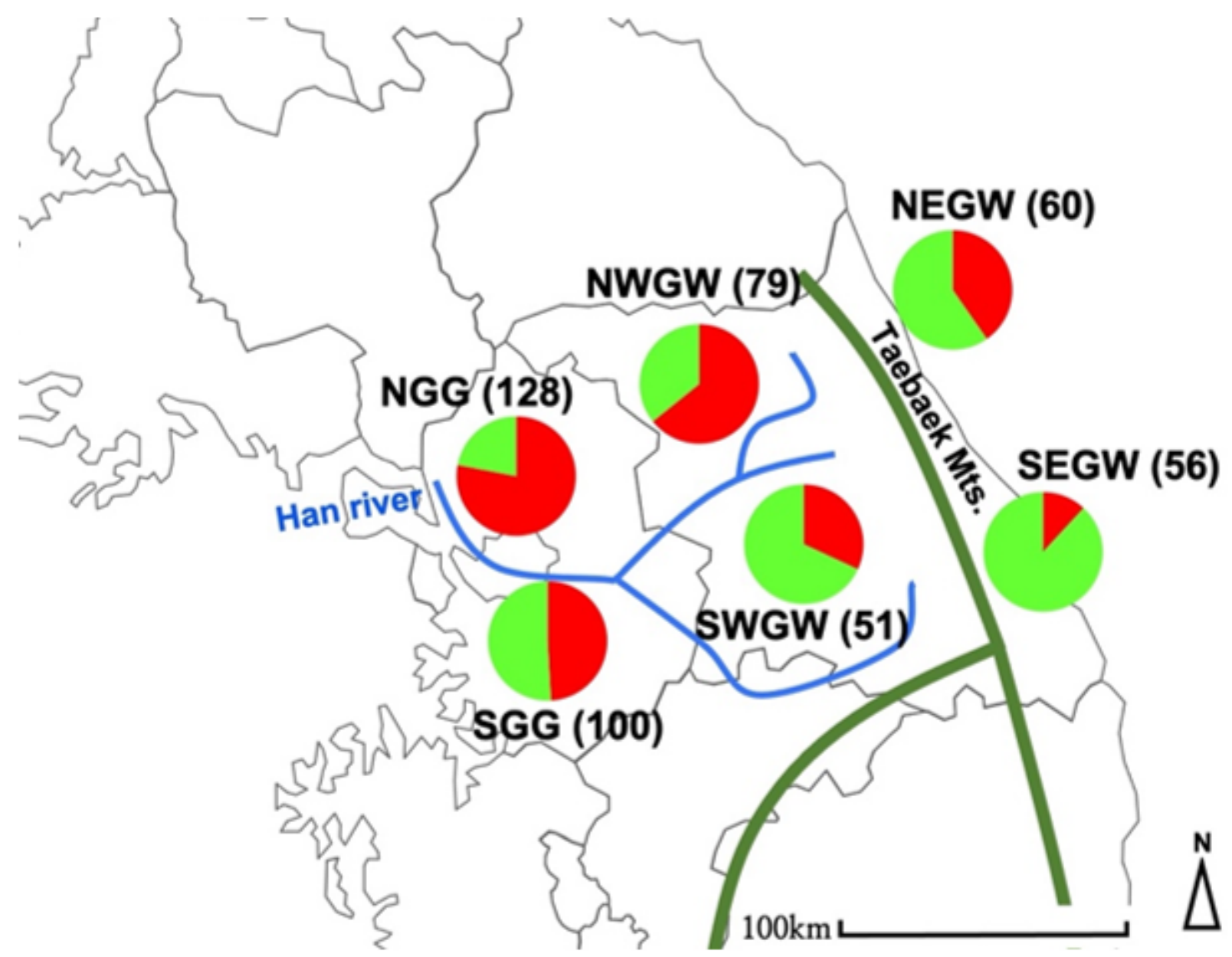

Figure 1

Study areas, including geographic features with sample size. Thick green lines represent Taebaek Mountains, while blue lines represent the Han River with its tributaries. Each pie chart shows the proportion of genetic clusters shown in Fig. 2. Check location abbreviations in Table 2 Note: The designations employed and the presentation of the material on this map do not imply the expression of any opinion whatsoever on the part of Research Square concerning the legal status of any country, territory, city or area or of its authorities, or concerning the delimitation of its frontiers or boundaries. This map has been provided by the authors.

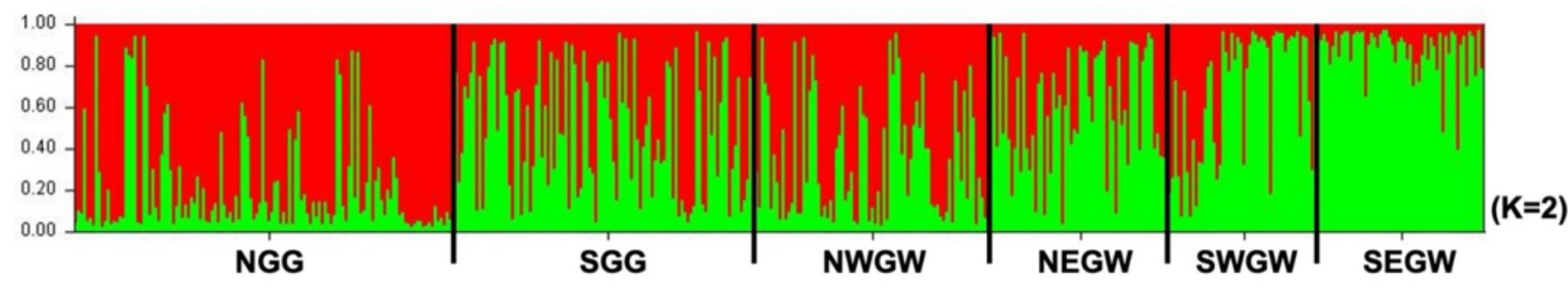

Figure 2 
Bar plots of wild boar populations recruiting from 2 genetic clusters as obtained by STRUCTURE v.2.3.4 analysis. The optimal number of $\mathrm{K}$ was approximately $\mathrm{K}=2$. Check location abbreviations in Table 2

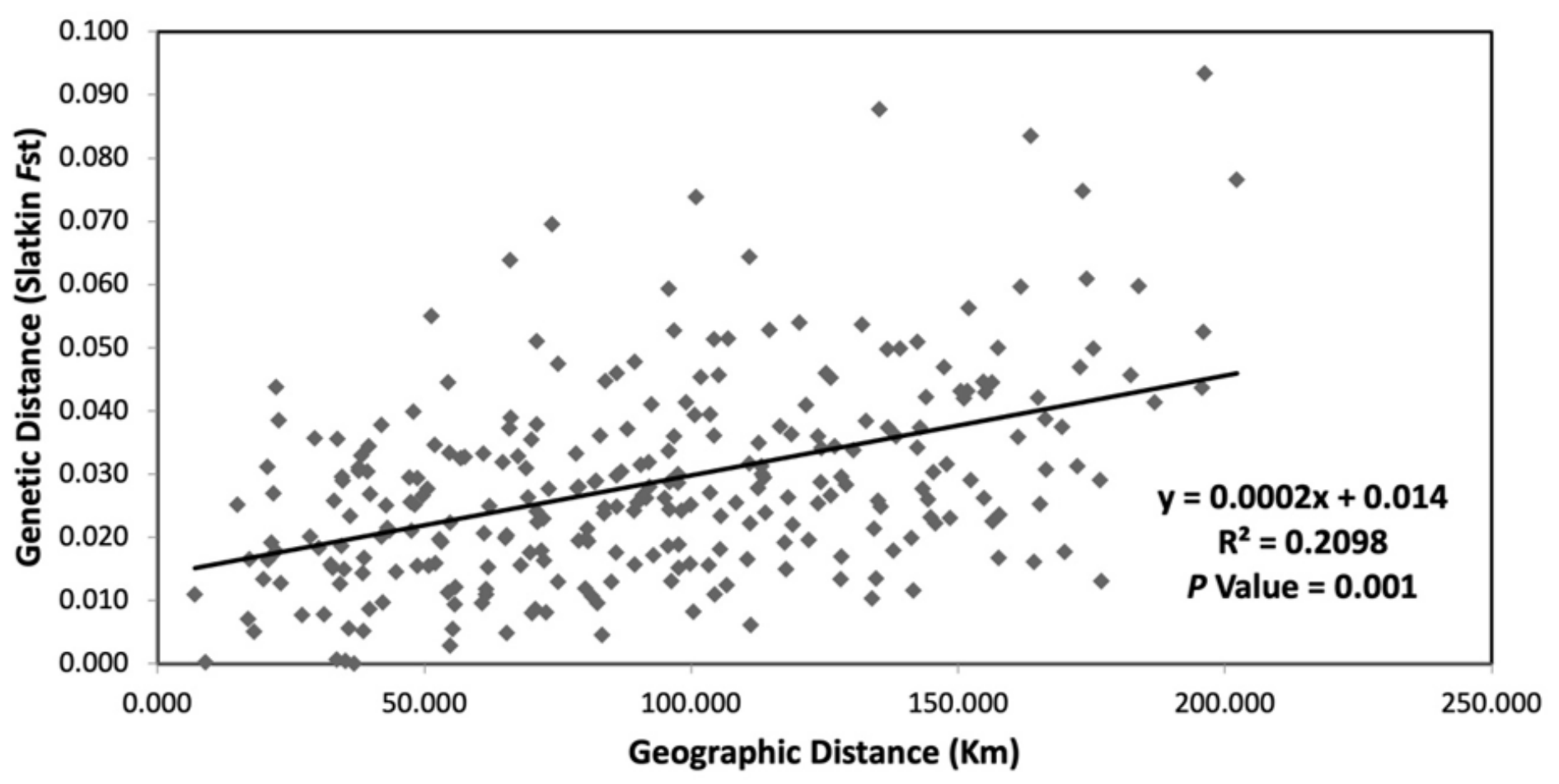

Figure 3

Isolation by Distance (IBD) analysis between genetic and geographic distances based on Mantel test with 999 permutations. Slatkin's linearized FST ( $\mathrm{D}=\mathrm{FST} /(1-\mathrm{FST}))$ were used 

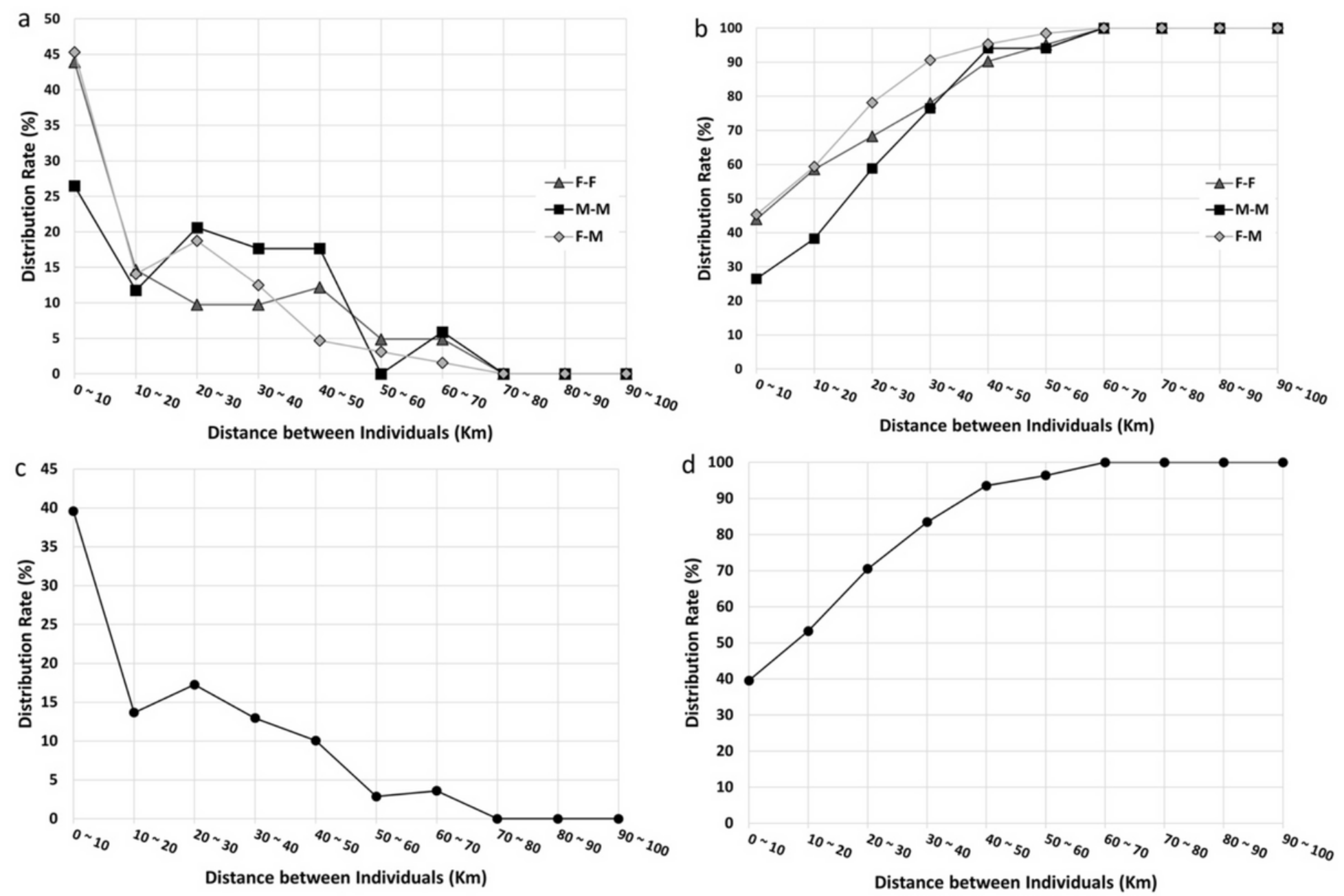

\section{Figure 4}

Distribution of distance proportions per $10 \mathrm{~km}$ sections according to sex. The triangle refers to a femalefemale pair, square refers to a male-male pair, while diamond refers to a female-male pair. b) Cumulative proportion of distance according to sex. c) Sex-integrated distribution of distance. d) Sex-integrated cumulative proportion of distance

\section{Supplementary Files}

This is a list of supplementary files associated with this preprint. Click to download.

- Supplementarymaterial.docx 